\title{
THE ROLE OF ENERGY MANAGEMENT FOR THE IMPLEMENTATION OF SUSTAINABLE AND EFFECTIVE HEAT PROCESSES \\ I. OPTIMAL ENERGY CONTROL OF HEAT PROCESSES IN THE CONDITIONS OF ANTIBIOTIC PROCESSING
}

\author{
Desislava Nikolova, Dragomir Dobrudzhaliev \\ Prof. Dr. Asen Zlatarov University, Burgas, Bulgaria \\ No. 1 „Prof. Yakimov” bvl., 8010 Burgas, Bulgaria \\ e-mail: d_nikolova@email.bg
}

\begin{abstract}
In this paper is described the developed by us method for optimal energy control in real production systems. The heat management role for the realization of sustainable and effective heating/cooling processes in the antibiotic production is evaluated. It was made and detailed energy technology analysis of antibiotic production, guaranteeing flawless and quality production. Adaptive software was developed based on the MATLAB programming environment, offering an optimal management solution to energy-related problems in certain production. The specific production criteria are taken into account by formulation a complex multi parametric optimization task. The approach can be applied to other productions (operating or designing) to optimal energy consumption management and energy efficiency.
\end{abstract}

Keywords: energy management, sustainable heat processes, antibiotic production.

\section{INTRODUCTION}

The ongoing global socio-economic crisis is putting global industry at risk. This makes the environment more vulnerable to pollution. Therefore, the minimization of energy consumption is called the sixth principle of "green chemistry", Anastas \& Warner (1998) [1]. The use of energy and raw materials in different batch systems requires improved efficiency in process management and waste minimization to meet environmental requirements, Thevendiraraj et al. (2003) [13], Kim JK, Smith R. (2004) [8].

On the other hand, good economic development, and employment and, last but not least, the competitiveness of the production unit must be ensured. This requires the development of a sustainable manufacturing. It is very difficult to achieve such steady growth in batch industries such as pharmaceutical, cosmetics, paint, food production, etc. There are a number of developments that suggest different methodologies for the energy management of batch productions. These approaches include: reducing the duration and increasing productivity Koulouris A. et al. (2000) [9], [7], Burkard R. E., Hatzl J. (2005) [2]; Wastewater reduction by reuse, timing optimization and / or purification Foo C. Y. et al. (2005) [5]; Majozi T. et al. (2006) [11], Cheng K. F., Chang C. T. (2007) [3], Waste Reduction Gyeongbeom Y., Reklaitis G. V. (2007) [6]; Reducing the need for resources C. Y. et al. (2005) [4]; Environmental impact assessment, Stefanis S. K. et al. (1997) [12]; Recovery of waste heat and / or integration of some of these approaches. Linainger et al. (1995) [10] create a package that integrates environmental and economic issues.

This work presents a method for optimal energy control developed by us in a real production system. A detailed technological analysis and monitoring of heating / cooling processes in antibiotic production has been carried out. On the basis of the audit, the application software

IRTIIE Vol. 5, No. 2, 2017 ISSN 1314-8788 (print), ISSN 1314-8796 (online), doi: 10.15547/artte.2017.02.005 
has been developed (in MATLAB's programming environment). An optimal management solution for the problems associated with energy consumption in particular antibiotic production is proposed. Specific features have been taken into account and a complex multiparametric optimization task has been formulated. The developed approach can also be applied to other productions (working or in the design stage) to optimize energy management and energy efficiency.

\section{AIM}

The aim of this work is to provide optimal energy control of heating processes in conditions of antibiotic production by minimizing energy consumption.

\section{MANAGEMENT OF ENERGY AND ENERGY CONSUMPTION}

The energy management has its permanent role in the modern industrial world in the implementation of sustainable and efficient technological processes. The energy management, respectively energy consumption includes a rich set of comprehensive measures aimed at minimizing energy costs while respecting the maximum profit condition. This set of measures covers several important strands. Some of which are:

$>$ Searching for and introducing new and unconventional energy sources that do not pollute the environment and are also calorific enough. The need to find and properly use for alternative energy sources is not new. Along with widely applied "green" energy sources are being studied and introduced into use and non-standard. For example, plans have already been developed for the world's first thorium nuclear reactor, it is proposed to place solar panels in space, to use salt water (osmotic energy or blue energy), etc .;

$>$ Optimising the use for secondary raw materials;

$>$ Increasing the percentage of waste (secondary) heat use. Waste heat that has been successfully recycled can greatly reduce the amount of purchased energy. It can be used directly in production or stored in heat tanks and used at a later time. Secondary energy can also be successfully used for a number of side-processing, , such as washing, packing, drying, etc. It is also possible to use as solve household energy problems, which are also in the cost of production.

$>$ Conducting energy - technological audit and analysis the possibilities for energy flows managing.

This paper presents a detailed technological analysis of an antibiotic production and focuses on the management, resp. optimizing heat energy from heating / cooling processes.

\section{PROBLEM DESCRIPTION}

One of the most common methods used for the production of antibiotics is the preparation of the substrate by fermentation. The fermentation is performed after cooling the sterilized nutrient to working temperature of $30^{\circ} \mathrm{C}$. Technical and cooled water is used for this process. The idea for managing energy consumption is in the unification of the heating / cooling processes. If a certain reactor is in a regime of cooling, then the released energy could be stored in a heat reservoir to use it for the preparation of nutrients in another reactor. This would save energy in the second reactor, and also reduce the technical water required for these processes. The idea can be implemented by designing a proper scheme. In addition, the control variables to ensure optimal energy managing in the two reactors should be identified. 


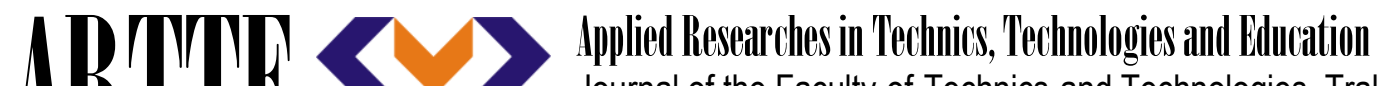 Journal of the Faculty of Technics and Technologies, Trakia University https://sites.google.com/a/trakia-uni.bg/artte/}

The technological process of antibiotic production includes the following stages:

\section{Stage 1: Nutrient preparation}

1. This process is carried out by mixing micelles and nutrient in a subsidiary reactor.

\section{Stage 2: Fermentation components}

1. Mixing of component $V_{1}$ from Tank $A$ with $V_{2.1 .}$ with water at $20^{\circ} \mathrm{C}(\mathrm{CW} 20)$ by stirring for 1 hour until nutrition medium NMA is obtained.

2. Mixing of component $V_{2}$ from Tank B with $V_{2.2 .} C W 20$ by stirring for certain time until nutrition medium $N M B$ is obtained.

\section{Stage 3: Fermentation process}

1. Transfer of $N M A$ to reactor $F_{C}$ and heat from $20^{\circ} \mathrm{C}$ to $55^{\circ} \mathrm{C}$.

2. Heat $N M A$ from $55^{\circ}$ to $100^{\circ} \mathrm{C}$ using Steam.

3. Sterilization of $N M A$ with $100^{\circ} \mathrm{C}$ steam for about $0.5 \mathrm{~h}$.

4. Transfer of $N M B$ to $F_{C}$ and mixing it with $N M A$ to obtain $A B_{-} I A B$.

5. Addition of $V_{3.5 .} C W 20$.

6. Heat the mixture $V_{C}$ with vapour to $T=55^{\circ} \mathrm{C}$ to obtain medium $N M A B$.

7. Heat the mixture $N M A B$ with water vapour from $55^{\circ} \mathrm{C}$ to $120^{\circ} \mathrm{C}$.

8. Sterilization of $N M A B$ with water vapour at temperature of $120^{\circ} \mathrm{C}$.

9. Cooling $N M A B$ from $120^{\circ} \mathrm{C}$ to $45^{\circ} \mathrm{C}$ using $C W 20$.

10. Cooling of $N M A B$ from $45^{\circ} \mathrm{C}$ to $30^{\circ} \mathrm{C}$ using $5^{\circ} \mathrm{C}$ cooled water ( $C W 5$ ).

11. Addition of $I M X$ to $N M A B$ up to volume $V_{\max }$ to obtain $F M$.

12. Cooling the medium $F M$ to $T_{\text {fer. }}$ using $C W 5$ and carry out fermentation for $120 \mathrm{~h}-150 \mathrm{~h}$ until the product $F B$ is obtained.

\section{Stage 4: Dilution}

1. Transfer $F B$ to an intermediate reservoir.

2. Addition of $V_{d}$ with water $C W 20$ for deactivation to obtain the product $D F B$.

\section{Stage 5: Filtration}

1. Filtering the $D F B$ to obtain concentrated material $D S C$.

Stage 6: Sterilization of the empty fermenter

1. Washing the empty fermenter with $C W 20$.

2. Sterilization of the washed fermenter with water vapour with temperature of $130^{\circ} \mathrm{C}$.

On the basis of the detailed en-technologist monitoring, a scheme for performing the heating/ cooling processes using heat tanks (Figure 1) is proposed. 


\section{IRTTIE Ipplied Researrohes in Technics, Technologies and Bducition Journal of the Faculty of Technics and Technologies, Trakia University https://sites.google.com/a/trakia-uni.bg/artte/}

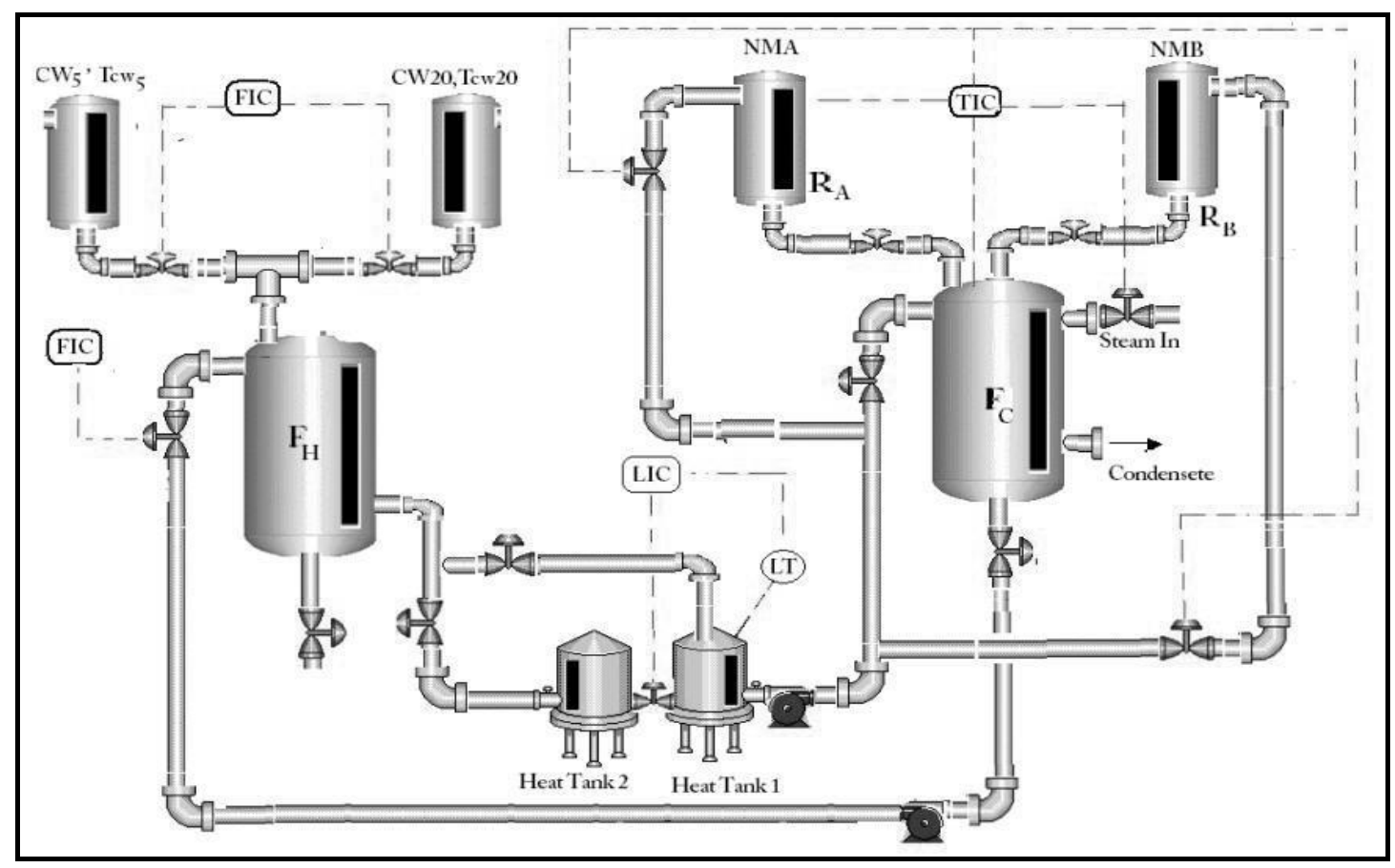

Figure 1. Technological scheme with heat reservoirs

The proposed management solution consists in the fact that water after serpentine is stored in two reservoirs, which perform the functions of heat reservoirs. The purpose is to be used the heated water after the coil, which is stored in the heat reservoirs to carry out nutrient preparation processes in another reactor.

A hot reactor is the fermenter $F_{H}$ where the processes of feeding the raw materials and sterilization. (3.1-3.7). At the end of the process (3.7) the mixture in the fermenter has a temperature $120^{\circ} \mathrm{C}$.It should be cooled down to temperature of $30^{\circ} \mathrm{C}$ to carry out fermentation.

In this case, it is not necessary to observe a specific schedule of reactors work in the manufacture. This leads to a reduction in the amount of wastewater and the water vapors used to heat/ cool the processes.

It is proposed that management of energy consumption by formulating complex multiparameter optimization task. To solve it, the MATLAB program environment is used. Software for managing the heat processes in the production of antibiotics has been developed.

The management essence output is the use of a minimal resource to carry out the heating processes.

$$
\operatorname{Cost}_{I N T}=\operatorname{MIN}\left\{\operatorname{Cost}_{\text {Steam }}^{*}+\operatorname{Cost}_{W 5}^{*}+\operatorname{Cost}_{\text {Water }}^{*}\right\}
$$

Where:

Cost ${ }_{\text {Steam }}^{*}$ - Steam expenses;

$\operatorname{Cost}_{W 5}^{*}$ - cooling water expenses $C W 5$;

Cost $_{\text {Water }}^{*}$ - Expenses of water used to carry out the processes in the cases when heat reservoirs are used.

IRTIIE Vol. 5, No. 2, 2017 ISSN 1314-8788 (print), ISSN 1314-8796 (online), doi: 10.15547/artte.2017.02.005 


\section{ARTITE Ipplied Researrohes in Technics, Technologies and Bducition Journal of the Faculty of Technics and Technologies, Trakia University https:///ites.google.com/a/trakia-uni.bg/artte/}

These components can be found using the following expressions:

$$
\left.\begin{array}{rl}
\operatorname{Cost}_{\text {Steam }}^{*}= & C_{\text {Steam }} C p_{W} V_{S 1}^{*}\left(T_{S t}^{*}-T_{S 1}^{*}\right)+ \\
& C_{\text {Steam }} C p_{W}\left(V_{F}-V_{S 1}^{*}\right)\left(T_{S t}^{*}-T_{W 20}\right), \\
\operatorname{Cost}_{W 5}^{*}= & C_{W 5} C_{F} V_{F}\left(T_{F 3}-T_{F 4}\right), \\
\operatorname{Cost}_{\text {Water }}^{*}= & C_{W 20}\left(\begin{array}{l}
\left(V_{\text {Water }}-V_{S 1}^{*}\right)+ \\
\left(V_{4.2 .}-V_{S 2}^{*}\right)+V_{S W}^{*}
\end{array}\right)
\end{array}\right\}
$$

Where:

$V_{\text {Water }}=V_{2.1 .}+V_{2.2 .}+V_{3.5 \text {; }}$

$C_{W 5}$ - Expenses of unit energy from $C W 5,[l v / k J]$;

$C_{\text {Steam }}$ - Expenses of unit energy from steam, $[l v / k J]$;

$C_{\text {Water }}$ - used water expenses, $\left[l v . / m^{3}\right]$.

This can be achieved by creating conditions for rate maximizing use of waste (second) heat energy. The search variables that can minimize the means used to carry out the heat processes are:

$$
\begin{aligned}
& \left\{A_{i}, B_{i}, C_{i}, t_{i}\right\}, \quad \forall i \in \overline{1,4} \\
& \left.x_{i}=\{0 \vee 1\}, y_{i}^{S 1}=\{0 \vee 1\}, y_{i}^{S 2}=\{0 \vee 1\}, \quad y_{i}^{S W}=\{0 \vee 1\}\right\}, \quad \forall i \in \overline{1,4}
\end{aligned}
$$

The constraints are related to the requirements of the technology towards the duration of the processes and the technical limitations of the cooling devices (serpentine).

$$
\left.\begin{array}{l}
\sum_{i=1}^{i=4} t_{i} \leq t_{f} \\
V_{S 1}^{*} \leq V_{2.1}+V_{2.2}+V_{3.5} \\
V_{S 2}^{*} \leq V_{\text {Waste }} \\
\sum_{i}^{S 2}\left(y_{i}^{S 1}+y_{i}^{S 2}+y_{i}^{S W}\right) \leq 1 \\
\left(y_{i}^{S 1}+y_{i}^{S 2}+y_{i}^{S W}\right)=x_{i}, \forall i \in \overline{1,4} \\
\operatorname{CoSt}_{I N T}<\text { CoSt }_{\text {NO_INT }} \\
T_{F 4} \leq T_{\text {fer }}
\end{array}\right\}
$$

$\operatorname{Cost}_{N O_{-} I N T}$ - Energy and water expenses, when the processes are carried out without energy management.

For the control, the variables (3) and (4) should be determined. These variables should give a minimum of the goal function (1) under the limitations posed by (5). The task is formulated 


\section{ARTTIE $Y$}

Ipplied Resseirlohes in Technics, Technologies and Bductation

Journal of the Faculty of Technics and Technologies, Trakia University https://sites.google.com/a/trakia-uni.bg/artte/

in the terms of Mixed Nonlinear Programming (MINLP) and is solved with the MATLAB programming environment.

The obtained results are summarized in Table 1. As a management result, there is a significant reduction in the cooling water $C W 20(65 \%)$ and the water $C W 5$ - increase by $3 \%$. At the same time, the steam amount is reduced at $35 \%$. Total energy savings (cooling water and steam) are approximately $29 \%$. The application of this type of energy managing eliminating the need for coordination of processes in time.

Table 1. Expenses of energy resource

\begin{tabular}{|l|l|c|}
\hline Expenses & $\begin{array}{c}\text { Expenses for a system } \\
\text { without applied energy } \\
\text { management } l w .\end{array}$ & $\begin{array}{c}\text { Expenses for a system with applied energy } \\
\text { management } \\
l w .\end{array}$ \\
\hline Cost $_{S T E A M}$ & 1168.40 & 720.84 \\
\hline Cost $_{W 20}$ & 377.15 & 161.24 \\
\hline Cost $_{W 5}$ & 389.89 & 527.95 \\
\hline Cost $_{S U M}$ & 1935.50 & 1410.00 \\
\hline
\end{tabular}

\section{CONCLUSION}

The presented study shows the energy - technological study of the heating processes in specific antibiotic production. Based on the audit, the application software was developed with MATLAB programming environment. Some specific features of production are defined and a complex multiparametric optimization task is formulated. The developed approach can also be applied to other industries (operating or designing) in order to optimally manage energy consumption and energy efficiency.

\section{REFERENCES}

[1] Anastas, P. T., and Warner, J. C. Green Chemistry: Theory and Prac-tice, Oxford University Press, 1998, Oxford.

[2] Burkard R. E., Hatzl J. Review, extensions and computational comparison of MILP formulations for scheduling of batch processes. Comput Chem Eng 2005;29:175269.

[3] Cheng K.F., Chang C. T. Integrated water network designs for batch processes. Ind Eng Chem Res 2007;46:1241-53.

[4] Foo C. Y., Manan Z. A., Yunus R. M., Aziz R. A., Synthesis of mass exchange network for batch processes. Part II. Minimun units target and batch network design. Chem Eng Sci 2005;60:1349-62

[5] Foo C. Y., Manan Z. A., Tan Y. L. Synthesis of maximum water recovery network for batch process systems. J Cleaner Prod 2005;13:1381-94.

[6] Gyeongbeom Y., Reklaitis G. V., Optimal design of batch-storage network with uncertainty and waste treatments. Am Inst Chem Eng 2007;52: 3473-90

[7] Ha J. K., Chang H. K., Lee E. S., Lee I. B., Lee B. S., Yi G. Intermediate storage tank operation strategies in the production scheduling of multi-product batch processes. Comput Chem Eng 2000;24:1633-40.

[8] Kim J. K., Smith R. Automated design of discontinuous water systems. Trans ChemE B 2004;82(B3):238-48

[9] Koulouris A., Calandranis J., Petrides D. P. Throughput analysis and debottlenecking of integrated batch chemical processes. Comput Chem Eng

IRTIIE Vol. 5, No. 2, 2017 ISSN 1314-8788 (print), ISSN 1314-8796 (online), doi: 10.15547/artte.2017.02.005 


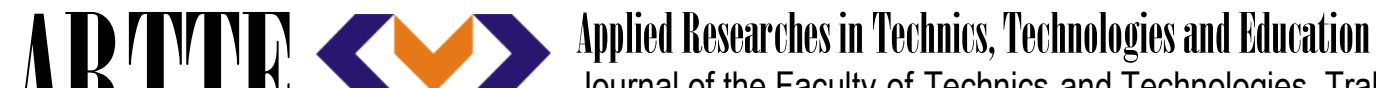 Journal of the Faculty of Technics and Technologies, Trakia University https://sites.google.com/a/trakia-uni.bg/artte/}

[10] Linainger A. A., Stephanopoulas E, Ali S. A, Han C., Stephanopoulos G. Generation and assessment of batch processes with ecological considerations. Comput Chem Eng 1995;19:7-13.

[11] Majozi T., Brouckaert C. J., Buckley C. A. A graphical technique for wastewater minimization in batch processes. J Environ Manage 2006;78:317-29.

[12] Stefanis S. K., Livingston A. G., Pistikopoulos E. N. Environmental impact considerations in the optimal design and scheduling of batch processes. Comput Chem Eng 1997;21:1073-94.

[13] Thevendiraraj S, Klemes J, Paz D, Aso G, Cardenas GJ. Water and wastewater minimisation study of a citrus plant. Resour Conserv Recycl 2003;37:227-50. 